\title{
Mild therapeutic hypothermia is superior to controlled normothermia for the maintenance of blood pressure and cerebral oxygenation, prevention of organ damage and suppression of oxidative stress after cardiac arrest in a porcine model
}

Petr Ostadal ${ }^{1 *}$, Mikulas Mlcek², Andreas Kruger', Svatava Horakova ${ }^{1}$, Marcela Skabradova ${ }^{1}$, Frantisek Holy ${ }^{1}$, Tomas Svoboda², Jan Belohlavek ${ }^{3}$, Vladimir Hrachovina ${ }^{2}$, Ludek Taborsky ${ }^{4}$, Vlasta Dudkova ${ }^{5}$, Hana Psotova ${ }^{1}$, Otomar Kittnar ${ }^{2}$ and Petr Neuzil ${ }^{1}$

\begin{abstract}
Background: Mild therapeutic hypothermia $(H T)$ has been implemented in the management of post cardiac arrest (CA) syndrome after the publication of clinical trials comparing HT with common practice (ie, usually hyperthermia). Current evidence on the comparison between therapeutic HT and controlled normothermia (NT) in CA survivors, however, remains insufficient.

Methods: Eight female swine (sus scrofa domestica; body weight $45 \mathrm{~kg}$ ) were randomly assigned to receive either mild therapeutic HT or controlled NT, with four animals per group. Veno-arterial extracorporeal membrane oxygenation (ECMO) was established and at minimal ECMO flow $(0.5 \mathrm{~L} / \mathrm{min})$ ventricular fibrillation was induced by rapid ventricular pacing. After 20 min of CA, circulation was restored by increasing the ECMO flow to $4.5 \mathrm{~L} / \mathrm{min}$; 90 min of reperfusion followed. Target core temperatures $\left(\mathrm{HT}: 33^{\circ} \mathrm{C}\right.$; NT: $\left.36.8^{\circ} \mathrm{C}\right)$ were maintained using the heat exchanger on the oxygenator. Invasive blood pressure was measured in the aortic arch, and cerebral oxygenation was assessed using near-infrared spectroscopy. After 60 min of reperfusion, up to three defibrillation attempts were performed. After 90 min of reperfusion, blood samples were drawn for the measurement of troponin I (Tnl), myoglobin (MGB), creatinephosphokinase (CPK), alanin-aminotransferase (ALT), neuron-specific enolase (NSE) and cystatin C (CysC) levels. Reactive oxygen metabolite (ROM) levels and biological antioxidant potential (BAP) were also measured.
\end{abstract}

Results: Significantly higher blood pressure and cerebral oxygenation values were observed in the HT group ( $\mathrm{P}<0.05)$. Sinus rhythm was restored in all of the HT animals and in one from the NT group. The levels of Tnl, MGB, CPK, ALT, and ROM were significantly lower in the HT group $(\mathrm{P}<0.05)$; levels of NSE, CysC, and BAP were comparable in both groups.

Conclusions: Our results from animal model of cardiac arrest indicate that HT may be superior to NT for the maintenance of blood pressure, cerebral oxygenation, organ protection and oxidative stress suppression following CA.

Keywords: Cardiac arrest, Mild hypothermia, Normothermia, Post-cardiac arrest syndrome, Extracorporeal membrane oxygenation, Cerebral oxygenation, Blood pressure, Organ protection, Oxidative stress

\footnotetext{
* Correspondence: ostadal.petr@gmail.com

${ }^{1}$ Cardiovascular Center, Na Homolce Hospital, Prague 15030, Czech Republic

Full list of author information is available at the end of the article
} 


\section{Background}

Mild therapeutic hypothermia (HT) was introduced into the clinical management of cardiac arrest survivors after the publication of the results of two clinical trials showing a benefit compared with standard treatment $[1,2]$, and has been included in the guidelines for post-cardiac arrest care from the American Heart Association [3] and the European Resuscitation Council [4]. The implementation of HT into clinical practice was also supported by metaanalyses of these clinical trials $[5,6]$. Recently, however, several authors presented a critical view of the current evidence for the protective role of HT in post-cardiac arrest syndrome. In analyses of the available randomized data, they showed that the evidence for the benefits of HT in cardiac arrest survivors remains inconclusive $[7,8]$. Their criticisms were based on the small size of published trials, low-quality data and non-negligible risks of systematic and random errors [7,8]. Furthermore, in the published studies, HT was compared with standard care without specific temperature management, ie, usually with spontaneously developed fever. The deleterious effects of fever and hyperthermia have been repeatedly observed in a wide population of critically ill patients [9] as well as in cardiac arrest survivors [10,11]. The relative lack of evidence regarding the benefits of mild therapeutic HT in cardiac arrest survivors has led to the establishment of a large multicenter randomized controlled trial comparing mild therapeutic HT with controlled normothermia (NT) in CA survivors (the Target Temperature Management trial), which is currently underway [12].

Presently, there is minimal research comparing mild therapeutic HT with controlled NT in either human studies [13] or animal experiments [14]. Therefore, the aim of the present study was to compare the effects of mild therapeutic HT and controlled NT on several clinically relevant outcomes in an animal model of cardiac arrest. We tested the hypothesis that mild HT is superior to controlled NT in the maintenance of blood pressure and cerebral oxygenation, resuscitability, prevention of organ damage and oxidative stress suppression after cardiac arrest in a porcine model.

\section{Methods}

The present study was approved by the Charles University $1^{\text {st }}$ Medical School Institutional Animal Care and Use Committee and performed at the Animal Laboratory, Department of Physiology, $1^{\text {st }}$ Medical School, Charles University in Prague, Czech Republic, in accordance with Act No 246/1992 Coll. regarding the protection of animals against cruelty.

\section{Animal model}

Eight female swine (Sus scrofa domestica, Landrace $\times$ Large white crossbreed), four to five months of age, with a mean body weight of $45 \mathrm{~kg}$ were included in the experiment. After $24 \mathrm{hr}$ of fasting, general anesthesia was induced by administration of azaperone $(2 \mathrm{mg} / \mathrm{kg} \mathrm{IM}$ ) followed by atropine sulphate $(0.02 \mathrm{mg} / \mathrm{kg} \mathrm{IM})$ and ketamine hydrochloride (15 to $20 \mathrm{mg} / \mathrm{kg} \mathrm{IM}$ ). Anesthesia was continued with initial propofol and morphine boluses ( $2 \mathrm{mg} / \mathrm{kg} \mathrm{IV}$ and 0.1 to $0.2 \mathrm{mg} / \mathrm{kg} \mathrm{IV}$, respectively) and animals were orotracheally intubated. Continuous IV infusions of propofol (8 to $10 \mathrm{mg} / \mathrm{kg} / \mathrm{hr}$ ) and morphine $(0.1$ to $0.2 \mathrm{mg} / \mathrm{kg} / \mathrm{hr}$ ) were used to maintain anesthesia. The doses were adjusted according to physiological parameters, photoreaction, corneal and palpebral reflexes, lacrimation and spontaneous movement. At the end of the experiment, potassium chloride $(2 \mathrm{meq} / \mathrm{kg})$ in conjunction with general anesthesia was used to euthanize animals.

Bilateral femoral (arterial and venous) and jugular approaches were used for multiple sheath insertions by the standard percutaneous Seldinger technique. An initial rapid IV infusion of $1000 \mathrm{ml}$ of normal saline was given after anesthesia induction, followed by a continuous IV drip of 200 to $500 \mathrm{ml} /$ hour to reach and maintain a mean right atrial pressure of 3 to $7 \mathrm{mmHg}$. An unfractionated heparin bolus (100 U/kg IV) was given after sheath placement, followed by a continuous IV infusion of $50 \mathrm{U} / \mathrm{kg} / \mathrm{h}$ to maintain an activated clotting time of 180 to $250 \mathrm{~s}$. Values were monitored every hour with the Hemochron Junior+ Microcoagulation System (ITC, USA).

Ventilation was provided by a Hamilton G5 ventilator (Hamilton Medical AG, Switzerland) set to INTELLiVENT Adaptive Support Ventilation (ASV) mode. The ventilator was set to maintain an $\mathrm{SpO}_{2}$ of $95 \%$ to $99 \%$, and an $\mathrm{EtCO}_{2}$ of 4.5 to $5.6 \mathrm{kPa}$. During the non-treated phase of cardiac arrest, the animals were not ventilated. During the ECMO-treated phase of cardiac arrest, minute ventilation was set and maintained at $100 \%$ of the predicted minute volume based on ideal body weight. The fraction of inspired oxygen was set to $21 \%$.

Ventricular fibrillation was induced by a high-frequency burst from a diagnostic decapolar catheter (Response CSL, St. Jude Medical, USA) advanced to the right ventricular apex through a jugular venous approach. The stimulation current amplitude was amplified to two times the pacing threshold.

\section{Vital functions monitoring}

Arterial pressure was measured using routine invasive pressure transducers (Truwave, Edwards Lifesciences, LLC, USA) through a pigtail catheter inserted into the aortic arch. A Swan-Ganz catheter was introduced via a femoral vein to the pulmonary artery. Electrocardiogram, invasive blood pressures (aortic arch and jugular vein), pulse oximetry, capnometry, core temperature (pulmonary artery) and invasive central venous oxygen saturation 
were continuously monitored in all animals (Monitor Life Scope TR, Nihon Kohden, Japan and Vigilance II, Edwards Lifesciences, USA). Brain oxygenation levels were measured using near-infrared spectroscopy (INVOS Cerebral/Somatic Oximeter, Somanetics, USA).

\section{ECMO}

The ECMO circuit consisted of a Levitronix Centrimag console (Thoratec, USA), centrifugal pump, and tubing set with HMO 70000 Adult Microporous Membrane Oxygenator with Softline Coating (MAQUET Cardiopulmonary AG, Germany) and a mechanical gas blender (Sechrist, USA). Biomedicus cannulae (Medtronic, USA) were introduced percutaneously using the standard Seldinger technique after repeated dilations of the femoral artery and vein. The venous inflow cannula (21F) was inserted into the inferior vena cava slightly below the right atrium (the tip position was checked by fluoroscopy) and the femoral arterial outflow cannula (15F) was inserted into the femoral artery. Body temperature was regulated and kept constant by the oxygenator heater unit. Blood gases were monitored continuously in the blood leaving the oxygenator $\left(\mathrm{CDI}^{\mathrm{Tm}}\right.$ Blood Parameter Monitoring System 500, Terumo Cardiovascular Systems Corporation, USA). During the non-treated phase of cardiac arrest, the pump flow rate was set to $0.5 \mathrm{~L} / \mathrm{min}$ and oxygen/air flow was stopped. During the ECMO-treated phase following cardiac arrest, the pump flow rate was set to $4.5 \mathrm{~L} / \mathrm{min}$ and oxygen/air flow was repeatedly adjusted to maintain $\mathrm{pO}_{2}$ and $\mathrm{pCO}_{2}$ in the ranges of 10 to $15 \mathrm{kPa}$ and 4.0 to $6.5 \mathrm{kPa}$, respectively, in blood leaving the oxygenator. The circuit, console function, and initial settings were controlled and directed by a perfusionist.

\section{Experimental protocol}

After insertion of all catheters and establishment of ECMO the animals were stabilized for $10 \mathrm{~min}$. Cardiac arrest was induced and maintained for $20 \mathrm{~min}$ before circulation was restored by increasing the ECMO flow rate to $4.5 \mathrm{~L} / \mathrm{min}(100 \mathrm{~mL} / \mathrm{kg} / \mathrm{min})$. After $60 \mathrm{~min}$ of reperfusion, defibrillation was attempted up to three times $(300-360-360 \mathrm{~J})$ to restore sinus rhythm, and the animals were followed for an additional $30 \mathrm{~min}$. The ECMO support continued the whole $90 \mathrm{~min}$ of reperfusion irrespective of defibrillation results (Figure 1).

Animals were randomly assigned to one of the two groups: NT or HT, with four animals per group. The core temperature of the animals in the NT group was maintained at $36.8^{\circ} \mathrm{C}$ throughout the experiment. The animals in the $\mathrm{HT}$ group were cooled to $33.0^{\circ} \mathrm{C}$ at the beginning of reperfusion; the target temperature was attained in $5 \mathrm{~min}$ in all HT animals and was maintained until the end of experiment.

To simulate clinical conditions, norepinephrine was administered when the mean arterial blood pressure remained below $60 \mathrm{mmHg}$ at $10 \mathrm{~min}$ after the restoration of circulation. The norepinephrine IV infusion was started at $0.2 \mu \mathrm{g} / \mathrm{kg} / \mathrm{min}$; this dose could be doubled or decreased by one-half at $15 \mathrm{~min}, 20 \mathrm{~min}$, and then every $10 \mathrm{~min}$ until the end of the experiment, with a maximal dose of $1.6 \mu \mathrm{g} / \mathrm{kg} / \mathrm{min}$.

\section{Laboratory tests}

Blood samples were drawn after 90 min of reperfusion and were immediately centrifuged. Serum was stored at $-70^{\circ} \mathrm{C}$ until levels of troponin I (TnI), myoglobin (MGB), creatine phosphokinase (CPK), alanine aminotransferase (ALT),

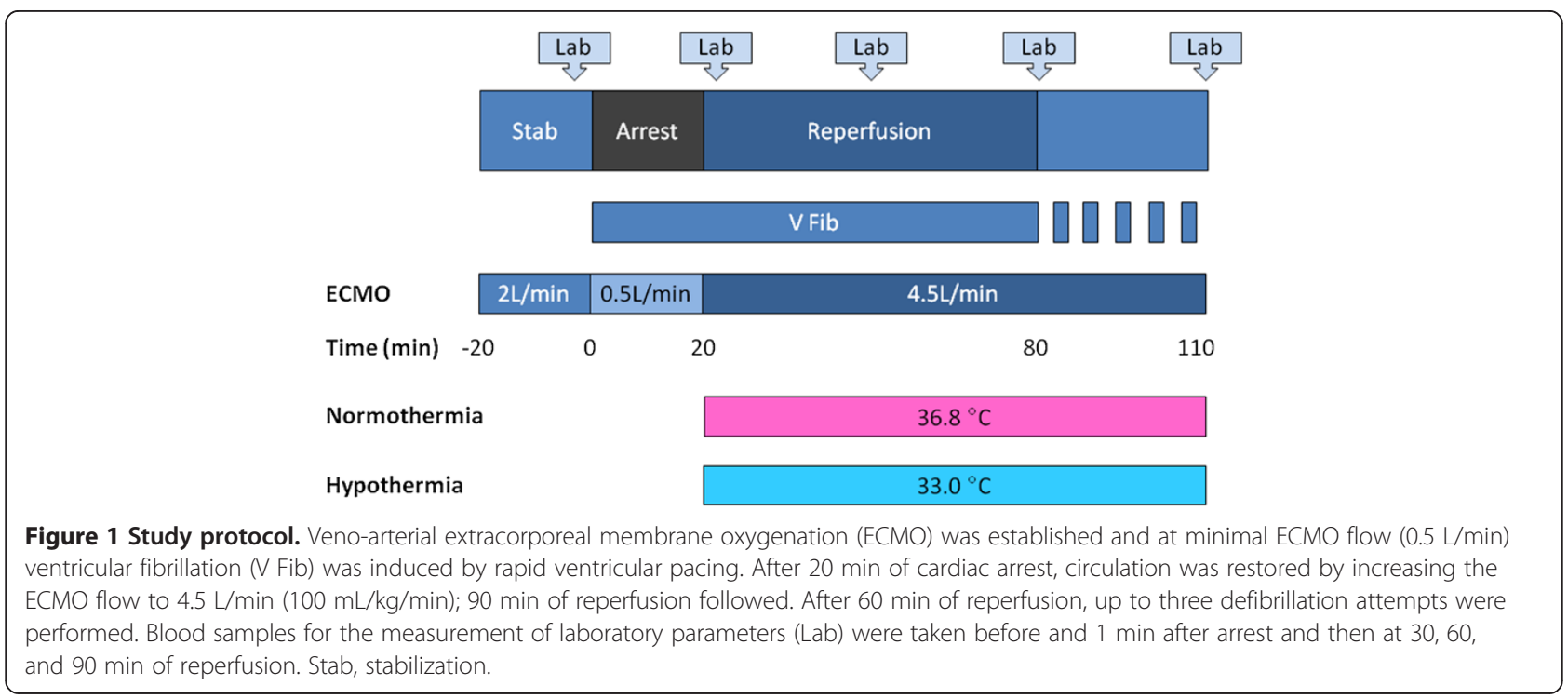


neuron-specific enolase (NSE), and cystatin C (CysC) were measured. Blood samples for the measurement of reactive oxygen metabolites (ROM) and biological antioxidant potential (BAP) were drawn before CA, 1 min after restoration of blood flow, and after 30,60 and 90 min of reperfusion. ROM and BAP tests were performed immediately after samples were obtained.

TnI and MGB levels were measured using a chemiluminescent immunoassay (Access Immunoassay System, Beckman Coulter Inc, USA). CPK and ALT levels were measured according to the method outlined by the International Federation of Clinical Chemistry, using the Synchron System (Beckman Coulter Inc, USA). NSE was measured with an immunoradiometric assay kit (Beckman Coulter, USA). CysC was measured with a Cystatin C immunoassay kit (Gentian AS, Norway) utilizing the immunoturbidimetric method. ROM and BAP were measured with the Fras 4 Evolvo free radical analytical system (H\&D srl, Italy).

\section{Statistical analysis}

Results are expressed as median (min; max). Mann Whitney test was used to assess differences between treatment groups in mean arterial blood pressure, norepinephrine dose, brain oxygen saturation, levels of oxidative stress markers (ROM and BAP) and all other laboratory parameters. Fisher's exact test was used to test for a difference in resuscitability. Differences were considered to be statistically significant at $\mathrm{P}<0.05$. All statistical analyses were performed using GraphPad Prism 5.0 software (GraphPad, USA).

\section{Results}

Blood pressure, brain oxygen saturation, resuscitability The mean arterial blood pressures, brain oxygen saturations and norepinephrine doses were not significantly different between treatment groups during the first 60 min of reperfusion (Figure 2). At 70, 80, and $90 \mathrm{~min}$, the mean arterial blood pressures and brain oxygen saturations were significantly higher in the HT group, despite the fact that the norepinephrine doses administered to this group were significantly lower compared with the NT group $(\mathrm{P}<0.05$; Figure 2). Defibrillation at $60 \mathrm{~min}$ was successful in all HT animals and in one of the NT animals after three attempts.

\section{Organ damage}

Laboratory parameters were analyzed in blood samples obtained at $90 \mathrm{~min}$ of reperfusion. Levels of ALT, CPK, MGB, and TnI were significantly lower in the HT group compared with NT group (ALT: $0.36(0.30 ; 0.55)$ versus 0.79 (0.65; 1.27) $\mu \mathrm{kat} / \mathrm{L}, \mathrm{P}<0.05$; CPK: 34.2 (26.0; 50.29) versus 86.0 (81.6; 117.8) $\mu \mathrm{kat} / \mathrm{L}, \mathrm{P}<0.05$; MGB: 379.8 (225.3; 566.0) versus 2423.0 (1995.0; 3442.0) $\mathrm{ng} / \mathrm{L}$,
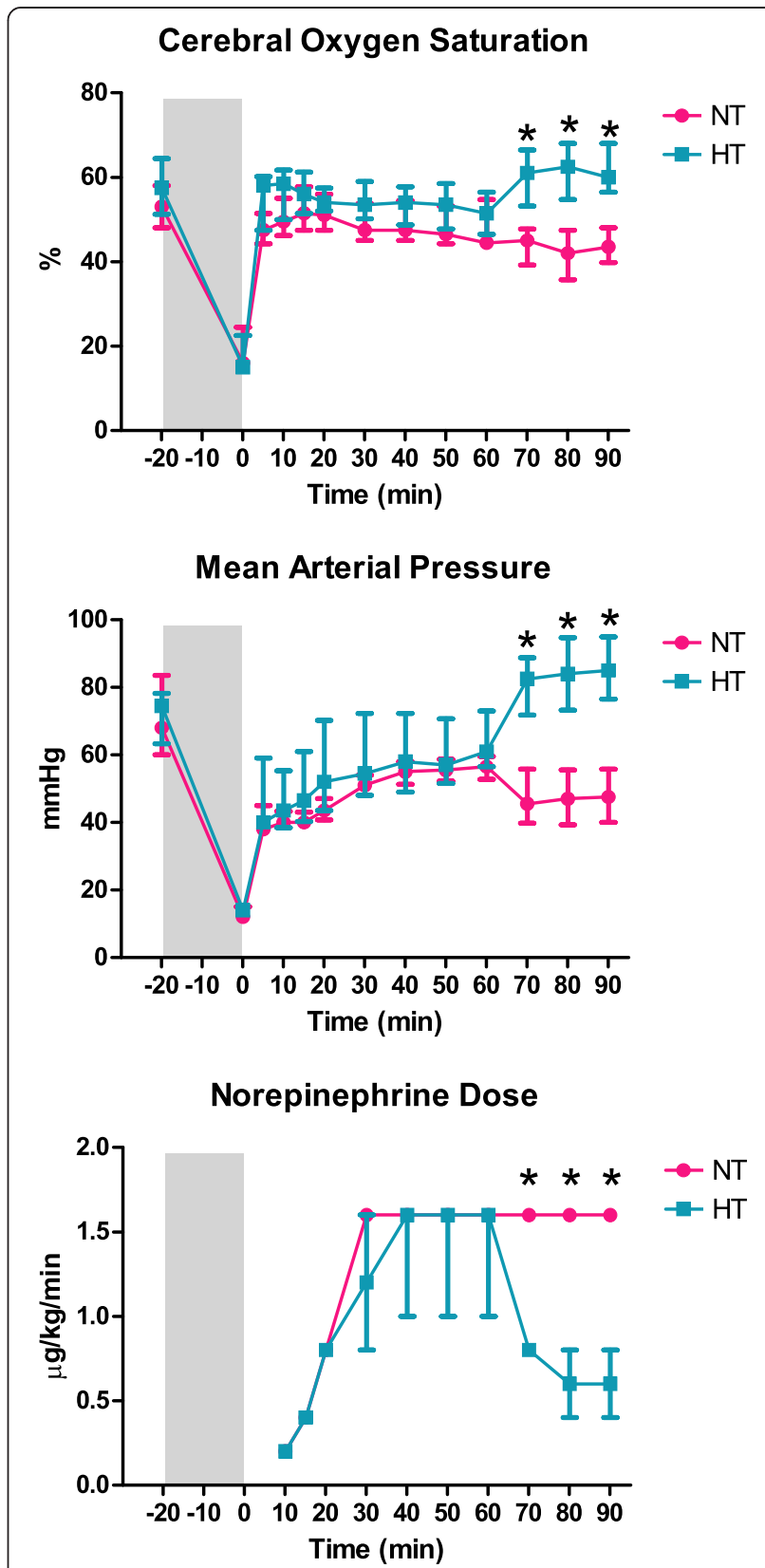

Figure 2 Brain oxygen saturation, mean arterial pressure and norepinephrine dose progression over the course of the experiment. Values are expressed as median (min; max). ${ }^{*} P<0.05$; NT normothermia; HT hypothermia.

$\mathrm{P}<0.05$; TnI: 4.8 (4.0; 12.2) versus $35.0(29.8 ; 42.2) \mathrm{ng} / \mathrm{L}$, $\mathrm{P}<0.05$ ) (Figure 3). The levels of both Cys $\mathrm{C}$ and NSE were close to the lower limit of detection, and no significant differences between the HT and NT groups were observed (Cys C: $0.01(0.01 ; 0.04)$ versus $0.02(0.1 ; 0.9)$ ng/L, $\mathrm{P}=0.62$; NSE: 0.77 (0.03; 1.53) versus 1.52 (1.29; 1.88) ng/L, $\mathrm{P}=0.31$ ) (Figure 3 ). 

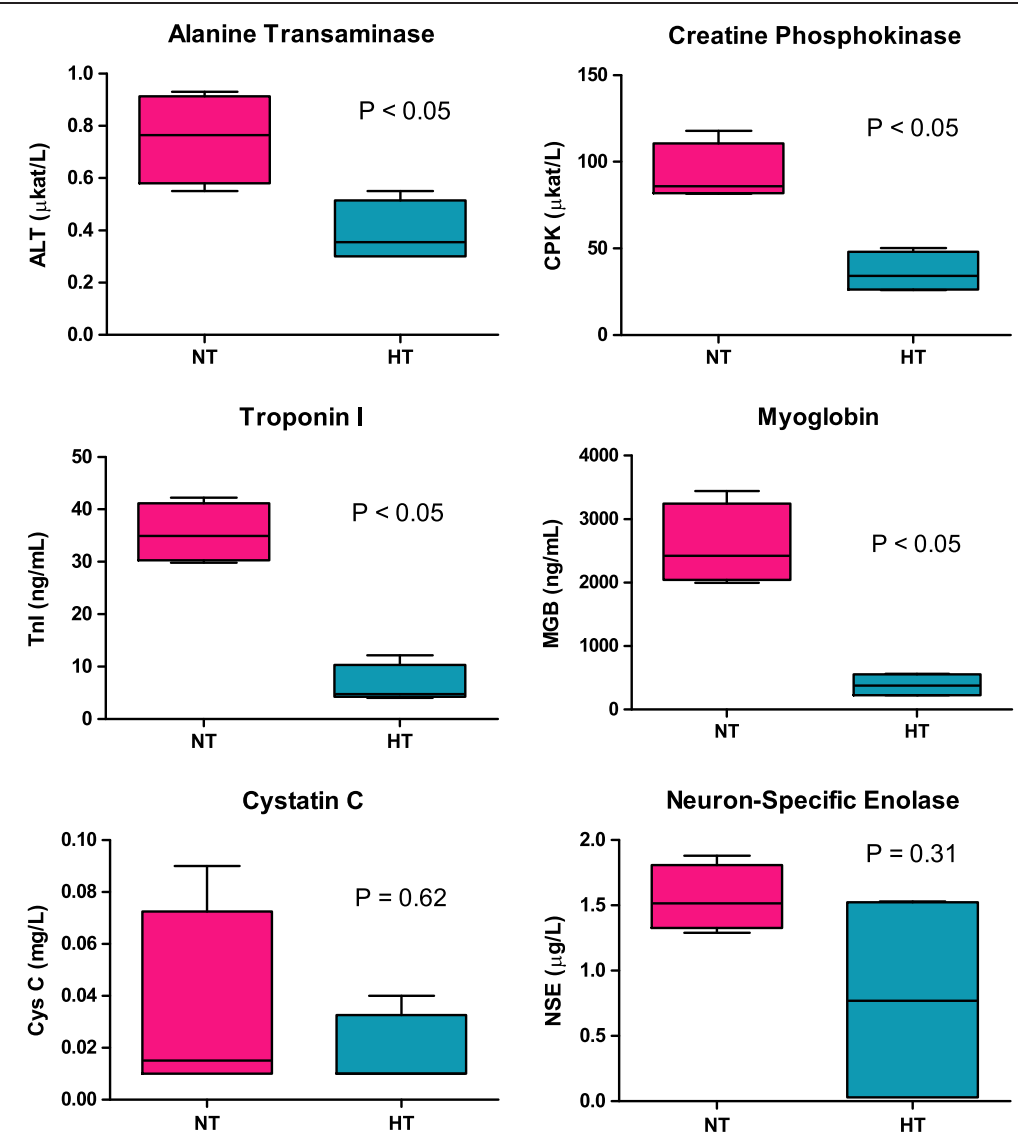

Figure 3 Serum levels of biomarkers of organ injury. Values are expressed as median (min; max). NT, normothermia; HT hypothermia.

\section{Oxidative stress}

The levels of ROM prior to and immediately after cardiac arrest were comparable between the HT and NT groups, but were significantly lower in the HT group in samples obtained at 30, 60 and $90 \mathrm{~min}$ of reperfusion (Figure 4). The levels of BAP were comparable between the HT and NT groups in all measurements.

\section{Discussion}

The present study found that mild therapeutic $\mathrm{HT}\left(33^{\circ} \mathrm{C}\right)$ is superior to controlled $\mathrm{NT}\left(36.8^{\circ} \mathrm{C}\right)$ for the maintenance of blood pressure and brain oxygen saturation, protection from organ damage and suppression of oxidative stress following cardiac arrest.

The use of mild therapeutic HT in the treatment of cardiac arrest survivors has recently been questioned due to a low level of evidence of its benefits $[7,8]$; in addition, spontaneous hyperthermia that may have occurred in the control patients in published clinical trials seems to be a significant risk factor $[10,11]$. However, to date, there have been few publications directly comparing mild therapeutic HT with controlled NT after
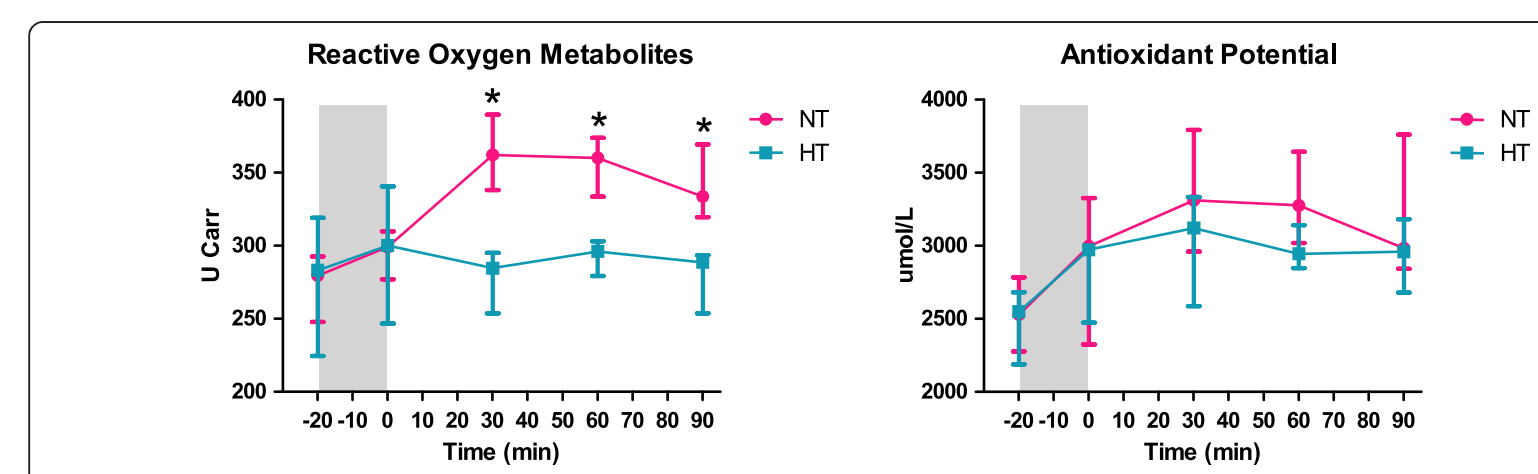

Figure 4 Serum levels of oxidative stress parameters. Values are expressed as median (min; max). NT, normothermia; HT hypothermia. 
cardiac arrest. In a rat model of resuscitated cardiac arrest, Jia et al. [14] found increased electroencephalography (EEG) bursts, followed by earlier restoration of continuous EEG activity and lower neurological deficit in rats treated with mild therapeutic HT compared with NT or hyperthermic animals. In a recent retrospective chart review, Horburger et al. [13] described that therapeutic HT is associated with a significant improvement in neurological outcome and 180-day survival compared with spontaneous NT in out-of-hospital cardiac arrest patients.

These studies are consistent with the observations in the present study. We found that HT-treated animals had higher blood pressure and brain oxygen saturation with lower norepinephrine consumption. However, these differences reached statistical significance only during the final $30 \mathrm{~min}$ of reperfusion, after successful defibrillation in all hypothermic animals whereas hemodynamically effective heart rhythm was restored in only one of four normothermic pigs. Despite that the rates of successful defibrillation were not significantly different it is likely that the increased blood pressure and brain oxygenation in the hypothermic group were influenced by higher rate of successful resuscitation. Moreover, the blood pressure differences between the HT and NT animals could be further increased by the continuous ECMO support, irrespective of the defibrillation results. On the other hand, blood pressure, tissue saturation, vasopressor consumption and heart rhythm are dependent parameters; therefore, from a clinical point of view, it is difficult to speculate which of these factors plays a more important role. Of note, the numerical values of blood pressure in the only NT animal with the return of effective heart rhythm after defibrillation were at least $10 \mathrm{mmHg}$ lower than the corresponding values from all hypothermic pigs despite higher norepinephrine dose.

We also observed lower levels of TnI, CPK, MBG and ALT in the HT group, indicating a protective effect of HT against myocardial, skeletal muscle and liver damage. The levels of CysC and NSE, markers of kidney and brain injury, were comparable in hypothermic and normothermic animals; however, these parameters were close to the lower limit of detection in both groups. It can, therefore, be assumed that $90 \mathrm{~min}$ of reperfusion is too short period to detect a substantial release of these markers into the circulation.

The lower levels of ROM during reperfusion in the HT group, together with comparable levels of BAP between groups, indicate that reactive oxygen species formation may be suppressed by HT, and a lower level of oxidative stress burden may occur in HT compared with NT. These results are consistent with our previous observations in the human population, in which induction of mild HT in cardiac arrest survivors was associated with a decreased production of nitrotyrosine and nitric oxide [15].
Our study has several limitations. First, we used only four animals per group that were followed for only ninety min after cardiac arrest; however, the present study was designed as a pilot experiment comparing the effects of HT and NT on clinically relevant parameters in a largeanimal model. Second, the restoration of blood flow by ECMO in most cardiac arrest cases is not typically performed in clinical settings. However, ECMO was used to eliminate the individual variability of blood flow after resuscitation, and ensured 'successful' restoration of circulation in all animals. Finally, the measurement of $\mathrm{CysC}$ and NSE levels as markers of kidney and brain injury failed to be usable for early organ injury detection; other markers should be used in future studies of similar design.

\section{Conclusions}

In porcine model of cardiac arrest, mild $\mathrm{HT}\left(33^{\circ} \mathrm{C}\right)$ was superior to controlled NT $\left(36.8^{\circ} \mathrm{C}\right)$ for the maintenance of blood pressure and cerebral oxygenation, prevention of organ damage and oxidative stress suppression after cardiac arrest. Prospective clinical trials are needed to confirm these experimental results, some of which are already underway.

\section{Abbreviations}

ALT: Alanin-aminotransferase; BAP: Biological antioxidant potential; CA: Cardiac arrest; CPC: Cerebral performance category; CPK: Creatinephosphokinase; CysC: Cystatin C; ECMO: Extracorporeal membrane oxygenation; EEG: Electroencephalography; HT: Mild hypothermia; MGB: Myoglobin; NSE: Neuron-specific enolase; NT: Controlled normothermia; ROM: Reactive oxygen metabolite; Tnl: Troponin I.

\section{Competing interests}

The authors declare that they have no competing interests.

\section{Authors' contributions}

PO, MM, OK, PN: study conception and design; AK, SH, MS, FH, TS, VH: animal experiment conduction, hemodynamic data acquisition, analysis, and interpretation; AK, HP: oxidative stress data acquisition, analysis, and interpretation; LT carried out immunoassays; VD carried out immunoradiometric assays; PO: manuscript drafting; JB, OK, PN: critical revision and final approval of the manuscript. All authors have read and approved the manuscript for publication.

\section{Acknowledgements}

The present study was supported by a grant from the Czech Ministry of Health, Nr. 12153.

\footnotetext{
Author details

${ }^{1}$ Cardiovascular Center, Na Homolce Hospital, Prague 15030, Czech Republic ${ }^{2}$ Department of Physiology, First Faculty of Medicine, Charles University in Prague, Prague 12000, Czech Republic. ${ }^{3}$ 2nd Department of Medicine Department of Cardiovascular Medicine, First Faculty of Medicine, General University Hospital and Charles University in Prague, Prague 12000, Czech Republic. ${ }^{4}$ Department of Clinical Biochemistry, Hematology, and Immunology, Na Homolce Hospital, Prague 15030, Czech Republic. ${ }^{5}$ Department of Nuclear Medicine, Na Homolce Hospital, Prague 15030, Czech Republic.
}

Received: 23 March 2013 Accepted: 15 May 2013 Published: 20 May 2013 
1. HACA-Study-Group: Mild therapeutic hypothermia to improve the neurologic outcome after cardiac arrest. N Engl J Med 2002, 346:549-556.

2. Bernard SA, Gray TW, Buist MD, Jones BM, Silvester W, Gutteridge G, Smith K: Treatment of comatose survivors of out-of-hospital cardiac arrest with induced hypothermia. N Engl J Med 2002, 346:557-563.

3. Peberdy MA, Callaway CW, Neumar RW, Geocadin RG, Zimmerman IL, Donnino M, Gabrielli A, Silvers SM, Zaritsky AL, Merchant R, et al: Part 9: post-cardiac arrest care: 2010 American Heart Association Guidelines for Cardiopulmonary Resuscitation and Emergency Cardiovascular Care. Circulation 2010, 122:S768-S786.

4. Deakin CD, Nolan JP, Soar J, Sunde K, Koster RW, Smith GB, Perkins GD: European Resuscitation Council Guidelines for Resuscitation 2010 Section 4. Adult advanced life support. Resuscitation 2010, 81:1305-1352.

5. Holzer M, Bernard SA, Hachimi-Idrissi S, Roine RO, Sterz F, Mullner M: Hypothermia for neuroprotection after cardiac arrest: systematic review and individual patient data meta-analysis. Crit Care Med 2005, 33:414-418.

6. Arrich J, Holzer M, Herkner H, Mullner M: Hypothermia for neuroprotection in adults after cardiopulmonary resuscitation. Cochrane Database Syst Rev 2009:CD004128.

7. Nielsen N, Friberg $\mathrm{H}$ : Insights from the evidence evaluation process-do we have the answers for therapeutic hypothermia? Resuscitation 2011, 82:501-502.

8. Nielsen N, Friberg H, Gluud C, Herlitz J, Wetterslev J: Hypothermia after cardiac arrest should be further evaluated-a systematic review of randomised trials with meta-analysis and trial sequential analysis. Int J Cardiol 2011, 151:333-341.

9. Badjatia N: Hyperthermia and fever control in brain injury. Crit Care Med 2009, 37:S250-\$257.

10. Zeiner A, Holzer M, Sterz F, Schorkhuber W, Eisenburger P, Havel C, Kliege A, Laggner AN: Hyperthermia after cardiac arrest is associated with an unfavorable neurologic outcome. Arch Intern Med 2001, 161:2007-2012.

11. Takasu A, Saitoh D, Kaneko N, Sakamoto T, Okada Y: Hyperthermia: is it an ominous sign after cardiac arrest? Resuscitation 2001, 49:273-277.

12. Nielsen N, Wetterslev J, al-Subaie N, Andersson B, Bro-Jeppesen J, Bishop G, Brunetti I, Cranshaw J, Cronberg T, Edqvist K, et al: Target Temperature Management after out-of-hospital cardiac arrest-a randomized, parallelgroup, assessor-blinded clinical trial-rationale and design. Am Heart $J$ 2012, 163:541-548.

13. Horburger D, Testori C, Sterz F, Herkner H, Krizanac D, Uray T, Schober A, Stockl M, Stratil P, Weiser C, et al: Mild therapeutic hypothermia improves outcomes compared with normothermia in cardiac-arrest patients-a retrospective chart review. Crit Care Med 2012.

14. Jia X, Koenig MA, Venkatraman A, Thakor NV, Geocadin RG: Post-cardiac arrest temperature manipulation alters early EEG bursting in rats. Resuscitation 2008, 78:367-373.

15. Kruger A, Ostadal P, Vondrakova D, Janotka M, Herget J: Nitrotyrosine and nitrate/nitrite levels in cardiac arrest survivors treated with endovascular hypothermia. Physiol Res 2012, 61:425-430.

doi:10.1186/1479-5876-11-124

Cite this article as: Ostadal et al: Mild therapeutic hypothermia is superior to controlled normothermia for the maintenance of blood pressure and cerebral oxygenation, prevention of organ damage and suppression of oxidative stress after cardiac arrest in a porcine model. Journal of Translational Medicine 2013 11:124.

\section{Submit your next manuscript to BioMed Central and take full advantage of:}

- Convenient online submission

- Thorough peer review

- No space constraints or color figure charges

- Immediate publication on acceptance

- Inclusion in PubMed, CAS, Scopus and Google Scholar

- Research which is freely available for redistribution

Submit your manuscript at www.biomedcentral.com/submit
C Biomed Central 